\title{
Um estudo sobre o trabalho com resolução de problemas após um curso de formação continuada em Matemática com professores dos anos iniciais do Ensino Fundamental
}

\author{
Giovana Pereira Sander, Universidade Estadual Paulista "Júlio de Mesquita Filho", Brasil \\ Nelson Antonio Pirola, Universidade Estadual Paulista "Júlio de Mesquita Filho", Brasil
}

\begin{abstract}
Resumo: A presente pesquisa teve como objetivo investigar a prática de ensino da Matemática por meio da resolução de problemas após a realização do curso do programa de formação continuada do Pró-Letramento. Participaram 458 cursistas do programa que são professores dos anos iniciais do Ensino Fundamental de municípios do estado de São Paulo/Brasil. Os instrumentos utilizados foram um questionário sobre as possíveis reflexões propiciadas pelo curso quanto ao ensino da Matemática e gravações de três aulas de Matemática de 4 professores. Os dados apontam que o curso contribuiu com a prática desses professores quanto à metodologia de ensino da Matemática, utilizando materiais concretos e jogos; e à compreensão dos conteúdos. Já o trabalho com a resolução de problemas foi algo pouco presente em suas falas. Durante o acompanhamento das aulas foi possivel observar que as situações problema são utilizadas para a aplicação de algoritmos anteriormente aprendidos. Apesar de o curso salientar sobre o ensino de conteúdos matemáticos através da resolução de problemas, tendo um momento especifico para discussões sobre essa temática, os professores trabalham com problemas após a explicação de um conteúdo, caracterizando-o, então, como exercícios.
\end{abstract}

Palavras-chave: resolução de problemas, formação continuada, ensino fundamental - ciclo I, pró-letramento

\begin{abstract}
This research aimed to investigate the practice of teaching mathematics through problem solving after the completion of the course of the continuing education of Pró-Letramento program. 458 persons participated of the program and they are teachers of the early years of elementary school from districts of the state of São Paulo / Brazil. The instruments used were a questionnaire about possible reflections offered by the course as the teaching of mathematics and recordings of three classes of four teachers of Mathematics. The data indicate that the course contributed to the practice of these teachers regarding the methodology of teaching mathematics, using concrete materials and games; and understanding of the content. In relation to work with problem solving, it was something with little presence in their speech. During the monitoring of lessons was observed that the problem situations are used for the application of previously learned algorithms. Although the course emphasize on teaching mathematical content through problem solving, having a specific time for discussions on this topic, teachers work with problems after the explanation of content, then characterizing it as exercise.
\end{abstract}

Keywords: Problem Solving, Continuing Education, Elementary Education - Cycle I, Pró-Letramento

\section{Introdução}

$\mathrm{E}$ ste artigo apresenta um recorte de uma pesquisa de dissertação de mestrado intitulada "PróLetramento: Um estudo sobre a resolução de problemas e as atitudes em relação à Matemática apresentadas por professores do primeiro ciclo do Ensino Fundamental".

Neste artigo, apresentamos metodologias e análise de dados que focaram o estudo sobre a resolução de problemas. Desta forma, tivemos o objetivo de investigar a prática de ensino da Matemática por meio da resolução de problemas após a realização do curso de formação continuada do Pró-Letramento. 


\section{Resolução de problemas}

A resolução de problemas é foco de estudos de diversos pesquisadores. De acordo com Sternberg (2000), nos empenhamos para resolver um problema quando queremos ou precisamos superar um obstáculo para atingir a finalidade de responder a uma pergunta ou alcançar um objetivo. A situação será apenas um problema quando não for possível recuperar na memória uma resposta de forma imediata. Caso contrário, não será um problema.

Echeverría (1998) salienta que

Para que possamos falar da existência de um problema, a pessoa que está resolvendo essa tarefa precisa encontrar alguma dificuldade que a obrigue a questionar-se sobre qual seria o caminho que precisaria seguir para alcançar a meta. (Echeverría, 1998, p. 48)

Os Parâmetros Curriculares Nacionais de Matemática (Brasil, 1997), diretrizes que orientam o trabalho de professores que atuam no Ensino Básico no Brasil, afirmam que "um problema matemático é uma situação que demanda a realização de uma sequência de ações ou operações para obter um resultado. Ou seja, a solução não está disponível de início, no entanto é possível construí-la" (BRASIL, 1997, p. 33). Quando encontramos a solução de forma imediata ou já conhecemos os procedimentos para isso, a situação acaba se caracterizando como um exercício.

De acordo com Brito (2006) um problema pode ser:

Uma situação inicial quase sempre desconhecida que é o ponto de partida. É o contato do sujeito com essa situação inicial desconhecida que permite a ele disponibilizar, na estrutura cognitiva, os elementos necessários à solução. Assim, através de uma série de operações realizadas a partir da situação inicial, o solucionador chega a um estado final definido (ou desejado) (Brito, 2006, p. 17).

Echeverría e Pozo (1998) e Sternberg (2000), apontam a diferença fundamental entre problema e exercício, sendo que neste último os mecanismos que levam à solução se encontram disponíveis em nossa mente de forma imediata. Segundo Echeverría (1998), resolução de problemas e exercícios possuem consequências diferentes no ensino da Matemática, assim como diferentes finalidades.

Os exercícios servem para consolidar e automatizar certas técnicas, habilidades e procedimentos necessários para a posterior solução de problemas, mas dificilmente podem trazer alguma ajuda para que essas técnicas sejam usadas em contextos diferentes daqueles onde foram aprendidas ou exercitadas, ou dificilmente podem servir para a aprendizagem e compreensão de conceitos (Echeverría, 1998, p. 48).

Saber diferenciar um do outro contribui com o trabalho de matemática em sala de aula, pois quando sabemos as finalidades de resolução de problemas e de exercícios e como elas interferem no processo de ensino e aprendizagem, é possível que o professor planeje o uso dessas atividades para atingir seus objetivos. Quando o objetivo é ensinar um conteúdo matemático novo, a melhor atividade para esse momento seria a resolução de problemas. Se o objetivo é o treino de algum algoritmo, a atividade mais adequada seria exercícios.

Os Parâmetros Curriculares Nacionais de Matemática (Brasil, 1997), assim como pesquisadores, tais como Brito (2006) e Moura et al. (2007) salientam que o ponto de partida de uma atividade matemática deve ser uma situação problema, e não a definição do conteúdo. No entanto, as pesquisas apontam que nem sempre isso acontece na prática em sala de aula, mostrando que esse tipo de atividade é trabalhado em diversas perspectivas.

A pesquisa de Galvão e Nacarato (2008), visando identificar e analisar as concepções de resolução de problemas presentes em livros didáticos dos anos iniciais do Ensino Fundamental analisou as três coleções mais indicadas por professores de uma rede municipal do interior de São Paulo ao Plano Nacional de Livro Didático (PNLD). De acordo com as pesquisadoras, a resolução de problemas é abordada nesses materiais em variadas perspectivas. Em uma delas, as situações-problema são encontradas no início, no meio e no final de um conteúdo, parecendo atividades que leva a construção de conceitos e não apenas exercícios de fixação. Em outra perspectiva, a resolução de pro- 
blemas é apresentada como um caminho para o ensino de matemática, sendo que é através de situações-problema que os conceitos matemáticos são ensinados.

$\mathrm{Na}$ pesquisa realizada por Souza (2013) sobre esse tema, a autora apresentou um relato sobre ações fundamentadas em pressupostos teóricos a respeito de resolução de problemas e utilização de jogos com o uso de roteiros baseados em estudos da literatura científica voltadas para metodologias de ensino. O roteiro era constituído pela introdução do conteúdo a ser ensinado a partir dos conhecimentos prévios dos alunos. Esses conhecimentos eram aplicados em jogos e atividades lúdicas. De acordo com a pesquisadora, os alunos demonstraram muito entusiasmo com as atividades propostas e ainda foi observado que eles compreendiam bem o que foi trabalhado durante o período.

Por fim, Trindade e Santos (2013) analisaram o uso de diferentes tipos de problemas matemáticos por professores de Matemática da rede municipal a fim de também buscar indícios da resolução de Problemas como metodologia. Segundo os pesquisadores, os problemas matemáticos são utilizados pelos professores após a exposição do conteúdo e como exercícios de reconhecimento de algorítmico. Eles também são utilizados como problemas de aplicação e quebra-cabeça, sendo que esses são voltados para alunos com maior potencialidade para criarem mais autonomia para o aluno, levantando e testando hipóteses, sendo mais questionador.

\section{Pró-Letramento em Matemática}

O Pró-Letramento era um programa de formação continuada de professores dos anos iniciais do Ensino Fundamental que buscava a melhoria da qualidade de aprendizagem na leitura/escrita da Língua Portuguesa e da Matemática. A realização do Programa ocorria basicamente por meio da atuação de alguns participantes: o formador, que era um professor vinculado a universidade e responsável pela formação do tutor; o tutor, que podia atuar na área de Alfabetização e Linguagem ou de Matemática e era responsável pela formação do professor cursista; e o cursista, que era professor dos anos iniciais do Ensino Fundamental $\left(1^{\circ}\right.$ ao $5^{\circ}$ ano $)$.

A formação dos professores era constituída de dois momentos: Primeira etapa e Revezamento. Na primeira etapa os tutores realizavam sua formação na Universidade formadora para posteriormente regerem o curso do Pró-Letramento em seus municípios junto aos professores cursistas. Os professores cursistas recebiam sua formação em seus municípios com o tutor de uma das áreas de conhecimento. Durante o Revezamento, os tutores regressavam à Universidade formadora e aprofundavam seus estudos na área iniciado anteriormente. Já os professores cursistas, neste momento, revezavam o curso. Quem havia realizado o curso do Pró-Letramento em Alfabetização e Linguagem na Primeira etapa, no Revezamento realizava o curso de Matemática, e vice-versa.

Para a formação em ambas as áreas, foram elaborados materiais denominados fascículos cujos temas são trabalhados nos anos iniciais do Ensino Fundamental. Ao Pró-Letramento em Matemática foram dedicados 8 fascículos com os seguintes temas:

1. Números naturais;

2. Operações com Números Naturais;

3. Espaço e Forma;

4. Frações;

5. Grandezas e Medidas;

6. Tratamento da Informação;

7. Resolver Problemas: o lado lúdico do ensino da Matemática; e

8. Avaliação da Aprendizagem em Matemática nos anos iniciais.

Os fascículos de 1 a 6 abordavam os conteúdos matemáticos que os professores ensinam durante o referido nível de ensino, enquanto que os fascículos 7 e 8 tratavam de temas relacionados à metodologia de ensino e de avaliação.

Os estudos dos fascículos aconteciam, preferencialmente, na sequência que são enumerados, ou seja, primeiro eram estudados os conteúdos matemáticos e posteriormente, fascículos referentes à metodologia. Quando não eram estudados nessa sequência, era porque o tutor preferiu iniciar o curso pelo fascículo sobre avaliação, mantendo, logo após, a ordem dos fascículos. 
O fascículo 7, Resolver Problemas: o lado lúdico do ensino da Matemática, foco do presente estudo, foi desenvolvido por Moura et al. (2007). As autoras tiveram o objetivo de aliar a resolução de problemas ao jogo no ensino de Matemática de forma com que a resolução de problemas fosse o ponto central do material e o jogo fosse uma situação problema a ser apresentada de forma lúdica.

No fascículo, um problema é caracterizado pela tomada de consciência do sujeito diante de uma situação onde se encontra e procura solucioná-la movido pela necessidade ou desejo de assim fazer. Para solucionar a situação, o sujeito dispõe de uma atividade mental intensa para planejar, executar e avaliar suas ações. Desta forma, o sujeito se depara com um problema quando se vê numa situação nova que o motive e que o envolva em um processo criativo e reflexivo.

Como metodologia de ensino da Matemática escolar, Moura et al. (2007) apresentam a resolução de problemas de duas formas, a saber:

- Utilizar a resolução de problemas após a explicação dos conteúdos: Quando trabalhamos com a resolução de problemas desta forma, os alunos já têm conhecimento de qual conteúdo ou procedimento deverão utilizar para resolver a situação. Assim, a situação problema acaba se caracterizando como um exercício, pois assume um papel de exercitar algoritmos e técnicas de solução, sem apresentar significado nenhum para os alunos. A situação problema não desperta a curiosidade do aluno, tampouco a vontade e a necessidade para solucionar a situação, tendo em vista que eles já conhecem os mecanismos que levam à sua solução de modo imediato.

- Utilizar a resolução de problemas antes da explicação dos conteúdos: Ao trabalhar os conteúdos matemáticos partindo de situações problema faz com que o aluno mobilize seus conhecimentos, desencadeie a construção de outros e ainda atribua significado às situações matemáticas. Desta forma, a resolução de problemas é tida como a "mola propulsora da Matemática".

Além da definição de resolução de problema e como esse tema deve ser trabalhado, o fascículo também discute diferentes tipos de problema, processos de resolução apresentados por alunos, avaliação da resolução de problemas e por fim, como trabalhar com resolução de problemas por meio de jogos.

\section{Metodologia}

O objetivo desta pesquisa foi investigar a prática de ensino da Matemática por meio da resolução de problemas após a realização do curso do programa de formação continuada do Pró-Letramento.

Para isso, a pesquisa foi realizada em dois momentos. No primeiro momento, participaram da coleta de dados 458 professores cursistas do programa do Pró-Letramento que são professores dos anos iniciais do Ensino Fundamental de municípios do estado de São Paulo/Brasil. O instrumento utilizado foi um questionário sobre as possíveis reflexões propiciadas pelo curso quanto ao ensino da Matemática. No segundo momento, foram acompanhadas e gravadas três aulas de Matemática de 4 professores cursistas selecionados. A seleção desses professores foi por meio da pontuação dos sujeitos em uma escala de atitudes ${ }^{1}$. Este momento teve a finalidade de investigar a prática pedagógica com resolução de problemas desses professores após cursar o Pró-Letramento, bem como se eles colocaram em prática os estudos do fascículo referente a essa temática.

\section{Análise dos dados}

A coleta de dados foi realizada por meio de um questionário, no qual 458 professores responderam, e de acompanhamentos das aulas de matemática de 4 professoras que realizaram o curso do PróLetramento como cursistas.

Uma das perguntas presente no questionário era sobre as reflexões que o Pró-Letramento de Matemática contribuiu com o trabalho dos professores em sala de aula. Pelas respostas dos professores, as reflexões puderam ser categorizadas, de forma geral, em "temas amplos", "atitudinais", "procedimentos" e "conceituais". A tabela a seguir apresenta essas reflexões.

\footnotetext{
${ }^{1}$ A escala de atitudes é um instrumento de pesquisa que busca mensurar as atitudes dos participantes em relação à Matemática. Essas atitudes foram utilizadas como critério de seleção dos professores cursistas para atingir os objetivos dessa pesquisa na íntegra.
} 
Tabela 1: Distribuição dos participantes de acordo com as reflexões geradas pelo Pró-letramento em sala de aula

\begin{tabular}{|c|l|c|c|}
\hline $\begin{array}{c}\text { Categorias } \\
\text { das reflexões }\end{array}$ & \multicolumn{1}{|c|}{ Reflexões } & Participantes & $\%$ \\
\hline \multirow{5}{*}{$\begin{array}{c}\text { Temas } \\
\text { amplos }\end{array}$} & Reflexões voltadas para a didática em sala de aula & 162 & 35.37 \\
\cline { 2 - 4 } & Troca de experiências entre o grupo/atividades dos encontros & 21 & 4.59 \\
\cline { 2 - 4 } & Reconhecer o uso da matemática no dia-a-dia & 11 & 2.40 \\
\cline { 2 - 4 } & Reflexões que envolvem outras etapas do ensino & 10 & 2.18 \\
\cline { 2 - 4 } & Entender estratégias dos alunos & 24 & 5.24 \\
\hline Atitudinais & Segurança para enfrentar as dificuldades do cotidiano & 16 & 3.49 \\
\hline \multirow{5}{*}{ Procedimentos } & Uso de materiais concretos em atividades & 72 & 15.72 \\
\cline { 2 - 4 } & Uso do lúdico para ensinar Matemática & 57 & 12.45 \\
\cline { 2 - 4 } & Levar o aluno a refletir sobre situações problemas & 11 & 2.40 \\
\cline { 2 - 4 } & Com estratégias de avaliação & 4 & 0.87 \\
\cline { 2 - 4 } & Outra forma de iniciar um conteúdo em sala de aula & 2 & 0.44 \\
\hline \multirow{3}{*}{ Conceituais } & Compreensão sobre os conceitos matemáticos & 35 & 7.64 \\
\cline { 2 - 4 } & Esclarecendo dúvidas & 17 & 3.71 \\
\cline { 2 - 4 } & Revisar os conteúdos da Matemática & 8 & 1.75 \\
\hline \multirow{3}{*}{ Outras } & Outras & 6 & 1.31 \\
\cline { 2 - 4 } & Desconsideradas & 25 & 5.46 \\
\cline { 2 - 4 } & Não respondeu & 2 & 0.44 \\
\hline
\end{tabular}

Fonte: Elaboração própria, 2014.

Pela tabela 1, podemos observar que o Pró-Letramento em Matemática gerou diferentes tipos de reflexões, sendo que algumas serão destacadas. Na categoria "temas amplos", 35,37\% dos participantes evidenciaram que suas reflexões estiveram voltadas para a didática em sala de aula de uma forma geral.

Outros aspectos apontados pelos professores foram quanto aos procedimentos de ensino da Matemática, sendo que $15,72 \%$ dos professores destacaram o uso de materiais concretos e $12,45 \%$ ressaltaram sobre o uso do lúdico durante o ensino. Nesta categoria, 2,4\% dos professores salientaram sobre levar o aluno a refletir sobre situações problemas. Outros 2 professores $(0,44 \%)$ apontaram sobre a forma de iniciar os conteúdos matemáticos durante as aulas. Tendo em vista que o curso do Pró-Letramento defende que o início do ensino de um novo conteúdo deve ser por meio da resolução de problemas, podemos pensar na possibilidade de esses professores estarem se referindo sobre este tipo de atividade.

As reflexões geradas pelo curso do Pró-Letramento também estiveram voltadas para aspectos conceituais da disciplina, sendo que 7,64\% assinalaram compreender melhor os conceitos matemáticos e $3,71 \%$ esclareceram dúvidas sobre os conteúdos.

Também foi questionado aos professores cursistas se eles acreditavam que sua prática em sala de aula estava se modificando com a realização do curso. Nesta questão, as respostas dos professores foram divididas, basicamente, em "sim" e "não". Dos 458 professores que responderam ao questionário, 9 afirmaram que não estavam atuando nos anos iniciais do Ensino Fundamental, mas sim na coordenação da escola, sala de recursos, Educação Infantil, entre outros; e 3 deixaram a questão em branco. Dos demais, 440 professores $(96,07 \%)$ salientaram que ocorreram mudanças em suas práticas nas aulas de Matemática enquanto que para apenas 9 professores (1,97\%) não houve mudanças.

A tabela 2 apresenta as respostas dos professores que acreditam que suas práticas nas aulas de Matemática foram modificadas, sendo que essas respostas foram categorizadas e, posteriormente, agrupadas pelos tipos de comentários. Os comentários sobre o que em sua prática mudou foram distribuídos nos seguintes grupos: metodológicos, conceituais e atitudinais. 
Tabela 2: Distribuição dos participantes de acordo com os comentários sobre as possíveis mudanças na prática em sala de aula

\begin{tabular}{|c|c|c|c|}
\hline $\begin{array}{c}\text { Categorias dos } \\
\text { comentários }\end{array}$ & Comentários & Participantes & $\%$ \\
\hline \multirow{11}{*}{ Metodológicos } & Está aprimorando a metodologia das aulas & 108 & 23.58 \\
\hline & Teve mais sugestões de atividades & 50 & 10.92 \\
\hline & Passou a utilizar mais materiais concretos & 21 & 4.59 \\
\hline & Passou a trabalhar mais com o lúdico & 21 & 4.59 \\
\hline & Reflete mais sobre o que ensina & 16 & 3.49 \\
\hline & O desempenho dos alunos melhorou & 18 & 3.93 \\
\hline & Mudou a forma de avaliar o ensino & 7 & 1.53 \\
\hline & $\begin{array}{l}\text { Procura adequar os conteúdos de acordo com as necessidades dos } \\
\text { alunos }\end{array}$ & 8 & 1.75 \\
\hline & Não está modificando, mas sim complementando & 6 & 1.31 \\
\hline & Passou a valorizar o conhecimento prévio da criança & 3 & 0.66 \\
\hline & Está trabalhando com outras estratégias para resolução de problemas & 3 & 0.66 \\
\hline \multirow{2}{*}{ Conceituais } & Está aprendendo mais com o curso & 51 & 11.14 \\
\hline & Por estar esclarecendo as dúvidas, fica mais fácil trabalhar & 11 & 2.40 \\
\hline \multirow{4}{*}{ Atitudinais } & Percebe as mudanças nos relatos durante o curso/trocas de experiência & 28 & 6.11 \\
\hline & Se sente mais segura para ensinar Matemática & 25 & 5.46 \\
\hline & As aulas estão mais prazerosas, significativas e interessantes para os alunos & 19 & 4.15 \\
\hline & O curso está servindo para aperfeiçoamento profissional & 10 & 2.18 \\
\hline \multirow{2}{*}{ Outros } & "Sim" & 16 & 3.49 \\
\hline & Outros & 11 & 2.40 \\
\hline
\end{tabular}

Fonte: Elaboração própria, 2014.

Pela tabela 2, podemos observar que os aspectos que mais obtiveram mudanças após o curso do PróLetramento, segundo os professores, foi quanto à metodologia de ensino da Matemática de uma forma geral. Assim, 23,58\% dos professores, ao afirmar que estavam aprimorando as metodologias utilizadas, salientaram que suas aulas ficaram mais dinâmicas, utilizando novas técnicas para ensinar, outras formas de explicar os conteúdos, que acreditavam que antes trabalhavam de forma mecânica, entre outras justificativas. Outros $10,92 \%$ dos participantes frisaram que o curso ofereceu diversos tipos de atividades para serem trabalhados; 4,59\% passaram a utilizar mais materiais concretos durantes suas aulas de Matemática; e $4,59 \%$ passaram a trabalhar mais com o lúdico, utilizando jogos. Entretanto, apenas $0,66 \%$ dos professores salientaram que começaram a utilizar outras estratégias para trabalhar com resolução de problemas.

Ainda, 11,14\% dos professores responderam que estavam aprendendo com o curso do PróLetramento e que esses conhecimentos novos estão sendo colocados em prática. De acordo com os questionários dos professores, esses conhecimentos estão relacionados com diversos conceitos matemáticos, tais como os "porquês" dos procedimentos de operações matemáticas e o uso do vocabulário correto de termos matemáticos, como, por exemplo, os nomes das figuras geométricas.

Já a tabela 3 apresenta as respostas dos professores que acreditam que suas práticas nas aulas de Matemática não foram modificadas após realizarem o curso do Pró-Letramento.

Tabela 3: Distribuição dos participantes de acordo com os comentários sobre não ter mudado a prática em sala de aula

\begin{tabular}{|l|c|c|}
\hline Comentários & Participantes & $\%$ \\
\hline Está seguindo o mesmo trabalho de antes & 3 & 0.66 \\
\hline Ainda se sente insegura & 2 & 0.44 \\
\hline Busca trabalhar de forma interdisciplinar & 2 & 0.44 \\
\hline Está apenas relembrando o que já estudou & 1 & 0.22 \\
\hline A prática não, mas a forma de pensar sobre a matemática, sim & 1 & 0.22 \\
\hline Total & 9 & 1.97 \\
\hline
\end{tabular}

Fonte: Elaboração própria, 2014. 
No total, apenas $9(1,97 \%)$ professores não modificaram suas práticas de ensino de Matemática. Desses, ao que se refere a metodologias de ensino, $3(0,66 \%)$ professores realçaram estar seguindo o mesmo trabalho de antes, por não ter aprendido o que desejavam, ou que mudariam quando trabalhasse na turma que fosse preciso mudanças. Outros $2(0,44 \%)$ professores que também não mudaram, salientaram que buscam trabalhar de forma interdisciplinar. Por fim, 1 professor estava apenas revendo os conteúdos que já havia estudado e outro enfatizou que não mudou a prática, mas sim a forma de ver a Matemática.

O acompanhamento das aulas de 4 professoras que realizaram o curso do Pró-Letramento apresentou dados sobre seus trabalhos com resolução de problemas que estão representados no quadro abaixo. Este quadro foca os tipos de situações problema que as professoras trabalharam; quais procedimentos as professoras utilizavam para trabalhar com as atividades de resolução de problemas junto aos alunos; quais recursos foram apresentados ou disponibilizados aos alunos, podendo ser materiais concretos ou outros materiais utilizados que auxiliaram nas atividades de resolução de problemas; e outros aspectos que seriam observações que diferenciou o trabalho de umas professoras das outras.

Quadro 1: Diferentes aspectos no trabalho com resolução de problemas apresentados pelos professores cursistas

\begin{tabular}{|c|c|c|c|c|}
\hline & $\begin{array}{l}\text { Tipos de } \\
\text { situações }\end{array}$ & Procedimentos & Recursos & Outros aspectos \\
\hline Prof. 1 & - Jogo & $\begin{array}{l}\text { 1. Explica o jogo; } \\
\text { 2. Acompanha uma rodada } \\
\text { em cada grupo; } \\
\text { 3. Os alunos jogam } \\
\text { sozinhos. }\end{array}$ & - & $\begin{array}{l}\text { Não trabalhou nenhuma situa- } \\
\text { ção-problema. }\end{array}$ \\
\hline Prof. 2 & $\begin{array}{l}\text { - Jogo } \\
\text { - Problema- } \\
\text { padrão }\end{array}$ & $\begin{array}{l}\text { 1. Lê e explica o problema; } \\
\text { 2. Indica um procedimento; } \\
\text { 3. Deixa os alunos } \\
\text { resolverem; } \\
\text { 4. Resolve com os alunos. }\end{array}$ & $\begin{array}{l}\text { - Desenho } \\
\text { - Tampa de } \\
\text { garrafa }\end{array}$ & $\begin{array}{l}\text { Utiliza materiais concretos, } \\
\text { mas não os disponibiliza para } \\
\text { os alunos os manipularem. }\end{array}$ \\
\hline Prof. 3 & $\begin{array}{l}\text { - Problema- } \\
\text { padrão }\end{array}$ & $\begin{array}{l}\text { 1. Pede para um aluno ler o } \\
\text { problema; } \\
\text { 2. Explica a situação; } \\
\text { 3. Indica um procedimento; } \\
\text { 4. Resolve com os alunos. }\end{array}$ & $\begin{array}{l}\text { - Ábaco } \\
\text { - Material } \\
\text { dourado } \\
\text { - Papel } \\
\text { quadriculado } \\
\text { - Imagens } \\
\text { impressas } \\
\end{array}$ & $\begin{array}{l}\text { Seguiu as atividades presentes } \\
\text { na apostila; } \\
\text { Modifica uma das situações } \\
\text { presente na apostila. }\end{array}$ \\
\hline Prof. 4 & $\begin{array}{l}\text { - Problema } \\
\text { do } \\
\text { cotidiano } \\
\text { - Problema- } \\
\text { padrão } \\
\text { - Problema } \\
\text { de lógica }\end{array}$ & $\begin{array}{l}\text { 1. Pede para um aluno ler o } \\
\text { problema; } \\
\text { 2. Pergunta para os alunos } \\
\text { como resolver a situação; } \\
\text { 3. Pede para os alunos } \\
\text { ditarem os } \\
\text { procedimentos do } \\
\text { algoritmo. }\end{array}$ & - & $\begin{array}{l}\text { Situações baseadas na realida- } \\
\text { de de seus alunos; } \\
\text { As atividades de resolução de } \\
\text { problemas apresentaram varias } \\
\text { situações; } \\
\text { Buscou atividade que permitis- } \\
\text { se que os alunos elaborassem o } \\
\text { enunciado; } \\
\text { Buscou que os alunos investi- } \\
\text { gassem diferentes soluções } \\
\text { para o problema. }\end{array}$ \\
\hline
\end{tabular}

Fonte: Elaboração própria, 2014.

O quadro 1 nos permite observar diversas diferenças quanto ao trabalho com atividades de resolução de problemas das professoras, mesmo todas elas terem cursado o Pró-Letramento e estudado o fascículo Resolver problemas: O lado lúdico do ensino da Matemática.

Durante o período do acompanhamento das aulas, a Prof. 1 trabalhou apenas com uma atividade de jogo. De acordo com Moura et al. (2007) esse tipo de atividade pode se caracterizar como resolu- 
ção de problemas, porém, na atividade proposta, não houve desafios que levassem os alunos a pensar em estratégias para chegar à solução. Por conta disso, podemos afirmar que, apesar de ser considerado um jogo, a atividade proposta pela professora foi um exercício, com treinos de um determinado algoritmo.

Já a Prof. 2 diversificou suas atividades de resolução de problemas em problema-padrão e jogo. Para os alunos compreenderem ou resolverem melhor as situações apresentadas nos problemaspadrão, ela mostrava materiais concretos que representassem as situações. No entanto, ela apenas os mostrava, sem permitir que os alunos manuseassem o material também.

A Prof. 3 trabalhou apenas com problemas-padrão que estavam presentes numa sequência de atividades da apostila utilizada por ela. Contudo, ela modificou o enunciado de uma das situações, o que resultou em uma resolução de problemas e não em um exercício. Isso porque, ao modificar o enunciado, a professora apresentou uma situação cuja resposta não era encontrada de forma pronta, ou seja, tiveram que pensar em procedimentos para encontrar a solução.

Por fim, a Prof. 4 foi a que mais diversificou seu trabalho com resolução de problemas, trabalhando com problemas do cotidiano, problema-padrão e problema de lógica. Um dos aspectos apresentados nessas atividades foi que os problemas do cotidiano tiveram os enunciados baseados em situações da realidade dos alunos e com uma sequência de situações problema para ser resolvida. Além disso, a professora propôs que seus alunos elaborassem um enredo para as situações e também instigou seus alunos a buscarem outras formas de resolver o problema. Ao resolverem as situações, os alunos demonstravam entusiasmo, pois os problemas eram todos "de verdade".

Quanto aos procedimentos utilizados durante as atividades, de forma geral, foram semelhantes: a situação era lida, era indicado um procedimento para a resolução e os alunos resolviam. O que mais variava era quem lia a situação, se era a professora ou os alunos. As discussões dos problemas ficavam restritas às estratégias de resolução. Quando o algoritmo era escolhido, as professoras não questionavam os alunos o porquê daquela escolha, perguntavam apenas como proceder com a estratégia.

Ainda, após a realização do algoritmo, as professoras elaboravam as repostas dos problemas baseadas nos resultados dos algoritmos que haviam feito. Não era feita uma avaliação sobre esses resultados, no sentido de se eles seriam o correto ou não, ou coerente com a situação proposta.

\section{Considerações finais}

A partir dos dados coletados por meio dos questionários e do acompanhamento das professoras, foi possível investigar a prática de ensino da Matemática por meio da resolução de problemas após a realização do curso de formação continuada do Pró-Letramento.

Quanto ao material elaborado para o curso do Pró-Letramento, havia uma sequência dos fascículos para ser estudado, sendo que, primeiramente eram trabalhados os fascículos que abordavam conteúdos matemáticos e, posteriormente, metodologias de ensino e de avaliação. Apesar dessa sequência, alguns tutores variavam essa ordem trabalhando com o fascículo sobre avaliação do ensino num primeiro momento, e mantendo a sequência dos demais fascículos. Ou seja, o fascículo sobre resolução de problemas, fascículo este sobre uma metodologia de ensino, era estudado pelos professores cursistas quando o curso já estava encerrando. Essa estrutura do curso fez com que não houvesse uma articulação entre o ensino dos conteúdos escolares com as atividades de resolução de problemas.

O fascículo Resolver problemas: O lado lúdico do ensino da Matemática diferencia problemas de exercícios, entre outros aspectos metodológicos sobre o tema. Por meio da análise dos questionários, foi possível observar que um dos aspectos que os professores mais salientaram foi que o PróLetramento contribuiu quanto ao uso do lúdico no ensino da Matemática. Mesmo esses dados não estarem diretamente relacionadas à resolução de problemas em suas falas, a ludicidade é um tema muito abordado no fascículo em questão.

Quanto ao trabalho com resolução de problemas em si, esse foi um tema pouco presente nas falas dos professores sobre as reflexões que o Pró-Letramento gerou ou com possíveis mudanças de suas práticas em sala de aula. 
De forma geral, os professores cursistas cujas aulas foram acompanhadas utilizam a resolução de problemas no processo de ensino e aprendizagem da Matemática escolar. As situações utilizadas estavam baseadas tanto no cotidiano dos alunos, como em situações hipotéticas, sendo que essas situações também estavam presentes nos livros didáticos utilizados pelos professores. Ainda, ao discutir essas atividades com os alunos, há uma tendência de os professores não permitirem que os alunos discutam a situação proposta, mas sim, os procedimentos a serem seguidos para a resolução. Desta forma, os alunos não discutiam suas interpretações diante das situações, discutiam apenas como resolver os algoritmos até encontrar um resultado.

Outro aspecto observado é se as situações propostas para os alunos se caracterizavam por problema ou exercício. Durante o acompanhamento das professoras em suas aulas de Matemática, foi possível observar que as atividades de resolução de problemas eram trabalhadas durante ou após o ensino de um conteúdo. Muitas situações apresentadas tinham como procedimento de resolução diversos conteúdos, como por exemplo, contas de adição e subtração no mesmo processo de resolução. No entanto, os alunos já estavam familiarizados com esses algoritmos, linguagens presentes no enunciado que os indicassem os procedimentos, as professoras davam "dicas" para eles descobrirem como resolver, entre outros. Esses aspectos, por sua vez, fizeram com que as atividades trabalhadas se caracterizassem por exercícios, pois os alunos precisavam apenas aplicar um conteúdo já apresentado pela professora.

Desta forma, conhecer procedimentos e aspectos peculiares do trabalho com resolução de problemas contribui para que o professor não tenha a falsa ilusão de trabalhar com esse tipo de atividade. Problemas e exercícios são atividades importantes para o ensino da matemática escolar, uma vez que mostram dois aspectos da aprendizagem: treino (exercícios) e o desenvolvimento da criatividade (resolução de problemas). 


\section{REFERÊNCIAS}

Brasil, MEC/SEF. Ministério da Educação e do Desporto - Secretaria de Ensino Fundamental. (1997). Parâmetros Curriculares Nacionais: Matemática / Secretaria da Educação Fundamental. Brasília, Brasil: D.F.

Brito, M. R. F. de. (2006). Alguns aspectos teóricos e conceituais da solução de problemas matemáticos. Em M.R.F. de Brito (Org.), Solução de problemas e a matemática escolar. (pp. 1353). Campinas, Brasil: Alínea Editora.

Echeverría, M. del P. P. (1998). A solução de problemas em Matemática. J.I. Pozo (Org.), A solução de problemas: Aprender a resolver, resolver para aprender (pp. 43-66). Porto Alegre, Brasil: Artmed.

Echeverría, M. Del P. P., e Pozo, J. I. (1998). Aprender a resolver problemas e resolver problemas para aprender. J,I, Pozo (Org.), A solução de problemas: Aprender a resolver, resolver para aprender (pp. 13-42). Porto Alegre, Brasil: Artmed.

Galvão, E. da S. e Nacarato, A. M. (2010). As abordagens de resolução de problemas presentes em livros didáticos para os anos iniciais. Perspectivas da Educação Matemática. Revista do programa de pós-graduação em educação matemática da UFMS, 3(6), pp.7-20.

Moura, A. R. L. de et al. (2007). Resolver problemas: o lado lúdico do ensino da matemática. Brasil, Ministério da Educação/SEB. Pró-Letramento: Programa de formação continuada de professores dos anos/séries iniciais do Ensino Fundamental: Matemática. - edição revista e ampliada incluindo SAEB / Prova Brasil matriz de referência / Secretaria de Educação Básica - Brasília: Ministério da Educação, Secretaria de Educação Básica.

Sander, G. P. (2014). Pró-Letramento: Um estudo sobre a resolução de problemas e as atitudes em relação à Matemática apresentadas por professores do primeiro ciclo do Ensino Fundamental. Dissertação (Mestrado). Universidade Estadual Paulista "Júlio de Mesquita Filho", Faculdade de Ciências, Bauru, Brasil.

Souza, E. R. F. de. (2013). Jogos e resolução de problemas: Construindo conceitos. XI Encontro Nacional de Educação Matemática. Educação Matemática: Retrospectivas e perspectivas. pp.1-10.

Sternberg, R. J. (2000). Resolução de problemas e criatividade. R. J. Sternberg (Org.), Psicologia Cognitiva (pp. 305-338). Porto Alegre, Brasil: Artmed.

Trindade, D. de A., e Santos, I. B. dos. (2013). Resolução de problemas: Metodologia ou recurso: (O caso de quinze professores de matemática de Aracaju). XI Encontro Nacional de Educação Matemática. Educação Matemática: Retrospectivas e perspectivas. pp.1-15.

\section{SOBRE OS AUTORES}

Giovana Pereira Sander: Possui graduação em Pedagogia pela Universidade Estadual Paulista "Júlio de Mesquita Filho" - Campus de Bauru (2010). Durante a graduação, desenvolveu pesquisas sobre relações entre o desempenho em resolução de problemas com alunos dos anos iniciais do Ensino Fundamental e suas atitudes em relação à Matemática. Atualmente é mestranda do Programa de Pós-graduação em Educação para a Ciência da mesma universidade. Participa do Grupo de Estudos em Psicologia da Educação Matemática, no qual desenvolve pesquisa sobre o ensino da Matemática através da resolução de problemas, com professores dos anos iniciais do Ensino Fundamental e atitudes em relação à Matemática em cursos de formação de professores, tanto em Licenciatura em Matemática como cursos de Pedagogia.

Nelson Antonio Pirola: Possui graduação em Matemática pela Universidade Estadual de Campinas (1991), mestrado em Educação (área de Concentração em Psicologia Educacional) pela Universidade Estadual de Campinas (1995) e doutorado em Educação (área de Concentração em Educação Matemática), pela Universidade Estadual de Campinas (2000). Possui livre-docência em Educação 
Matemática pela UNESP. Atualmente é professor adjunto do Departamento de Educação da Universidade Estadual Paulista Júlio de Mesquita Filho. Tem experiência na área de Educação, com ênfase em Formação de Conceitos e Solução de Problemas, atuando principalmente nos seguintes temas: educação matemática, formação de professores, solução de problemas, educação continuada e ensino de matemática. É diretor da Sociedade Brasileira de Educação Matemática - Regional São Paulo - Triênio 2008-2010 e 2011-2013 Atualmente é coordenador do curso de Pedagogia PARFOR (UNESP/CAPES). Docente credenciado no Programa de Pós-Graduação em Educação para a Ciência da UNESP - Bauru. 